American Journal of Pharmaceutical Education 2017; 81 (7) Article 5918.

\title{
RESEARCH
}

\section{Associations Between Pharmacy Students'Attitudes Toward Debt, Stress, and Student Loans}

\author{
Marie A. Chisholm-Burns, PharmD, MPH, MBA, ${ }^{a}$ Christina A. Spivey, PhD, ${ }^{b}$ Melanie C. Jaeger, BS, \\ Jennifer Williams, PharmD ${ }^{\mathrm{b}}$ \\ ${ }^{a}$ University of Tennessee College of Pharmacy, Memphis, Knoxville, Nashville, Tennessee \\ ${ }^{\mathrm{b}}$ University of Tennessee College of Pharmacy, Memphis, Tennessee \\ Submitted July 7, 2016; accepted October 14, 2016; published September 2017.
}

\begin{abstract}
Objective. To assess graduating pharmacy students' attitudes toward debt and determine associations with stress, student loan debt, financial need, current employment, post-graduation plans, and expected length of time to repay loans.

Methods. Survey was conducted using an attitudes-toward-debt scale (sub-scales: tolerant attitudes toward debt; contemplation and knowledge about loans; fear of debt), Perceived Stress Scale, and questions concerning current employment, estimated total student loan debt, post-graduation plans, and expected length of time to repay loans. Federal loan data were collected using financial aid records. Independent samples $t$-test, ANOVA, and Pearson's $r$ correlations were conducted.

Results. There were 147 students (96.7\%) who participated. The majority were female (59.2\%), white (69.4\%), and had federal student loans (90.5\%). Mean total loan amount was \$153,276 (SD \$59,810), which included federal students loans accumulated before and during pharmacy school. No significant differences were noted on attitudes toward debt or stress based on whether respondents had federal student loans. Greater "fear of debt" was correlated with increased stress, estimated total student loan debt, total federal loan debt, and pharmacy school loan debt. Greater "contemplation and knowledge about loans" was correlated with lower estimated total student loan debt, total federal loan amount, and pharmacy school loan amount. Students with higher "contemplation and knowledge" scores expected to repay loans within a shorter time frame than students with lower scores.

Conclusion. Increased fear of debt was related to greater perceived stress and higher student loan amounts borrowed, while increased contemplation and knowledge about loans was associated with lower amounts borrowed. Educational programming concerning loans, debt, and personal financial management may help reduce stress and amount borrowed.
\end{abstract}

Keywords: debt, student loans, stress, pharmacy students

\section{INTRODUCTION}

In recent years, a college education has become a bare minimum requirement for a vast number of entry- level jobs. As a result, college enrollment increased $24 \%$ between 2002 and 2012; however, while enrollment increased, so has the cost of a college education. ${ }^{1}$ According to the nonprofit student advocacy organization College Board, after adjusting for inflation, the average tuition and fees of a 4-year public institution was $40 \%$ higher in 2015 compared to 2005 and $26 \%$ higher in private institutions. ${ }^{2}$ As a result, many students borrow money to complete their education; in 2014 alone, almost $70 \%$ of graduating college seniors had

Corresponding Author: Marie Chisholm-Burns, University of Tennessee Health Science Center College of Pharmacy, 881 Madison Ave., Suite 264, Memphis, TN 38163. Tel: 901448-7141.Fax: 901-448-7053.E-mail: Mchisho3@uthsc.edu student loan debt. ${ }^{3}$ Thus, student loan debt, which increased 56\% between 2004 and 2014, has become a large financial burden for many Americans, with student loans in the U.S. totaling more than $\$ 1$ trillion dollars. ${ }^{3,4}$ Pharmacy and other health professions students in particular often have a high debt load. In 2016, almost $88 \%$ of graduating pharmacy students borrowed money to fund their education, with the average student's debt being $\$ 131,153$ for public institutions and $\$ 182,417$ for private institutions. ${ }^{5}$

Financial debt can be an overwhelming stressor. Debt, like lower socio-economic standing, has been shown to have detrimental effects on mental and physical health, and student loans impact students' lives for years after they have graduated. A study by Nelson and colleagues demonstrated that students with credit card debt over $\$ 1,000$ were more likely to feel significantly 


\section{American Journal of Pharmaceutical Education 2017; 81 (7) Article 5918.}

stressed. ${ }^{6}$ These students were also more likely to engage in physical altercations, binge drinking, tobacco and drug use, and were more prone to being overweight. ${ }^{6}$

Financial strain is often a catalyst for "stress proliferation," in which one stressor leads to the formation of multiple others. ${ }^{7,8}$ For example, Mott and colleagues indicated that pharmacists who bear a larger debt burden work much longer hours when they graduate, which may lead to an increase in stress level. ${ }^{9}$ A pharmacist's level of indebtedness also has the potential to impact choice of practice site, wherein a pharmacy student may forego a residency or choose a certain employer simply for higher pay opportunities. ${ }^{10}$ Subsequently, these pharmacists may feel less fulfilled in their position/employment. Additionally, significant debt can cause students to postpone important life events such as home ownership, marriage, or starting a family. ${ }^{11-14}$ For example, Gicheva found that graduate students were significantly less likely to get married as their student loan debt level increased. ${ }^{12,13}$

There is ample research concerning indebtedness and its impact on college students' well-being; however, only one study ${ }^{15}$ was found in the literature that explored pharmacy students' attitudes toward financial debt including student loans and factors that may affect these attitudes. No prior studies have examined the relationship between pharmacy students' attitudes toward debt and stress. Although needed, as this information may assist pharmacy schools in developing programs that better aid students in understanding and managing their debt, the literature on this topic is scarce. Therefore, the objectives of this study are to assess graduating pharmacy (P4) students' attitudes toward debt and determine associations between such attitudes and students' levels of perceived stress, demographic characteristics, estimated student loan debt level, actual student loan debt level, financial need designation, current employment, post-graduation plans, and expected length of time to repay student loans.

\section{METHODS}

The study design was a cross-sectional survey. All P4 students $(n=152)$ at the University of Tennessee College of Pharmacy were invited to participate in the survey that was distributed in May 2016, one week prior to graduation. Surveys were administered (distributed and collected) to students in a college classroom setting as they attended a required review course. Administration was done by a study coordinator. The survey took 1015 minutes to complete. Participation in the study was voluntary, no incentives were offered to students, and investigators were blinded to the identity of participants.
The study was approved by the University of Tennessee Health Science Center Institutional Review Board.

The survey instrument was used to collect the following data: attitudes toward debt, perceived stress, current employment (yes/no), estimated student loan debt (ie, how much students believe they currently owe in student loans accumulated prior to pharmacy school and during pharmacy school), post-graduation plans (ie, employment/training/educational plans within 6 months of graduation), and expected number of years to pay off student loans. In the survey, attitudes toward debt were measured using an 11-item scale developed by Park and colleagues, which has acceptable internal consistency as indicated by a Cronbach's alpha of .64. ${ }^{15-17}$ The scale items addressed financial debt in general as well as specific sources of debt including credit cards and student loans. Likerttype responses for each item range from $1=$ Strongly Disagree to $5=$ Strongly Agree, with 3 as a neutral value. Three items were reverse-coded (or worded in the opposite direction as the majority of scale items). The scoring of these items was reversed to be consistent with the direction of the scoring for the remaining eight items, meaning if the item response was 5 , it was scored as 1 (or vice versa); if the item response was 4, it was scored as 2 (and vice versa); and 3 remained unchanged as the neutral value. The attitudes toward debt scale includes three factors or sub-scales: "tolerant attitudes toward debt" (scores range from 4-20, with higher scores indicating more tolerant attitudes toward debt); "contemplation and knowledge about loans" (scores range from 4-20, with higher scores indicating greater contemplation and knowledge about loans); and "fear of debt" (scores range from 3-15, with higher scores indicating less fear of debt). ${ }^{15}$ The "tolerant attitudes toward debt" sub-scale and "contemplation and knowledge about loans" sub-scale consist of four items each, and the "fear of debt" sub-scale consists of three items. The "tolerant attitudes toward debt" sub-scale assesses how open students are to the idea of taking on debt. ${ }^{15}$ The "contemplation and knowledge about loans" sub-scale assesses how thoughtful students are regarding taking on debt and loans and if students are familiar with the terms of their loans. ${ }^{15}$ The "fear of debt" sub-scale assesses students' level of worry/ concern regarding debt. ${ }^{15}$

In the survey, perceived stress, or "the degree to which situations in one's life are appraised as stressful," was measured using the 10-item Perceived Stress Scale (PSS-10) developed by Cohen and Williamson. ${ }^{18,19}$ The PSS has undergone considerable testing, providing evidence of its validity and reliability. ${ }^{20-22}$ Roberti and colleagues reported a Cronbach's alpha of .89, indicating good internal consistency. ${ }^{16,17,22}$ Likert-type responses for each item range from $0=$ Never to $4=$ Very Often, 


\section{American Journal of Pharmaceutical Education 2017; 81 (7) Article 5918.}

with 2 as a neutral value. Four items were reverse-coded. The scoring of these items was reversed to be consistent with the direction of the scoring for the remaining six items. Scores on the PSS-10 range from 0-40, with higher scores indicating greater perceived stress.

Demographics (gender, race/ethnicity, age) and actual student loan debt were collected from official student records and financial aid records by the study coordinator and a financial aid officer, respectively. The demographic and student loan data were collated in a study database and matched to individual student survey data by the study coordinator. The coordinator then de-identified the database and transferred it to the investigators, and thus blinding of the investigators was maintained. Student loan data included total federal loans borrowed both prior to and during pharmacy school, amount of federal loans taken during pharmacy school (referred to as "pharmacy school loans"), amount of federal loans taken prior to pharmacy school, total amount paid toward student loans to date, and financial need designation (low need, low/medium, medium, medium/high, and high, as determined by the University of Tennessee Health Science Center Financial Aid Office).

Statistical analyses were performed using IBM SPSS Statistics 22.0 (Armonk, NY). Student characteristics were summarized by frequencies for categorical variables, and by means and standard deviations for continuous variables. Coding of categorical variables was as follows: gender, $0=$ male and $1=$ female; race/ethnicity, $0=$ non-Hispanic White, 1 = Other (due to limited numbers, other racial/ethnic groups were combined); current employment, $0=$ no and 1 = yes; post-graduation plans, $1=$ residency/fellowship, $2=$ employment, $3=$ other; expected number of years to pay off student loans, $0=$ no student loans, $1=$ less than 5 years, $2=5$ to 10 years, and $3=$ greater than 10 years; and financial need designation, $0=$ low, $1=$ medium-low, $2=$ medium, $3=$ mediumhigh, and $4=$ high. Internal consistency of the attitudes toward debt scale and PSS-10 were examined using Cronbach's alpha. Independent samples $t$-test was used to assess differences in attitudes toward debt sub-scale scores ("tolerant attitudes toward debt," "contemplation and knowledge about loans," and "fear of debt") based on gender, race, current employment, and whether respondents had federal student loans or not (coded as $0=$ no federal student loans, $1=$ has federal student loans). Analysis of variance (ANOVA) with Bonferroni post-hoc tests was used to assess differences in attitudes toward debt sub-scale scores based on post-graduation plans, expected number of years to pay off student loans, and financial need designation for each year of pharmacy school. Pearson's $r$ correlations were used to assess the strength of the relationships between attitudes toward debt sub-scale scores and age, PSS-10 score, estimated student loan debt amount, total federal loan amount, pharmacy school loan amount, prior to pharmacy school loan amount, and total amount paid toward student loans. The a priori significance level was .05 .

\section{RESULTS}

The response rate was $96.7 \%$ (147 of 152). The majority respondents were female $(59.2 \%)$ and white (69.4\%), distributions generally reflective of the national pharmacy student population which is approximately $61 \%$ female and $52 \%$ white. ${ }^{23}$ The majority of respondents were also currently employed (81.6\%). Mean (SD) age was 26.9 years (3.4), with the majority students $(89.9 \%)$ being 30 years of age or younger (this is similar to the national pharmacy graduating class of 2016, of which $84.9 \%$ was 30 years old or younger). ${ }^{5}$ The majority of respondents planned to pursue employment following graduation ( $\mathrm{n}=91$ or $61.9 \%)$; the remaining respondents planned to pursue residency or fellowship $(\mathrm{n}=55,37.4 \%)$ or other opportunities $(n=1, .7 \%)$.

Financial need designations for students for each year of pharmacy school are summarized in Table 1 . Among the respondents, 133 (90.5\%) borrowed federal student loans prior to pharmacy school, during pharmacy school, or both prior to pharmacy school and during pharmacy school. Forty-one (27.9\%) students stated they expected to pay off their loans in less than 5 years, 66 $(44.9 \%)$ in 5 to 10 years, and $28(19.0 \%)$ in greater than 10 years. Twelve students $(8.2 \%)$ stated that they currently had no student loans to pay off. This differs somewhat from financial aid records which indicated 14 (9.5\%) respondents had no history of borrowing federal student loans. These two groups of students were compared, and 9 students were in both groups. Among the five remaining students from the group $(n=14)$ with no history of federal student loans according to financial aid records, all stated they did have student loans to pay off in the survey

Table 1. Summary of Financial Need Designations for Each Year of Pharmacy School $(n=147)$

\begin{tabular}{lcccc}
\hline Designation & $\begin{array}{c}\text { Year 1 } \\
\mathbf{n}(\mathbf{\%})\end{array}$ & $\begin{array}{c}\text { Year 2 } \\
\mathbf{n}(\mathbf{\%})\end{array}$ & $\begin{array}{c}\text { Year 3 } \\
\mathbf{n}(\mathbf{\%})\end{array}$ & $\begin{array}{c}\text { Year 4 } \\
\mathbf{n}(\mathbf{\%})\end{array}$ \\
\hline Low & 0 & $7(4.8)$ & $7(4.8)$ & $12(8.2)$ \\
Medium-Low & $19(12.9)$ & $9(6.1)$ & $6(4.1)$ & $1(.7)$ \\
Medium & $73(49.7)$ & $3(2.0)$ & $3(2.0)$ & $2(1.4)$ \\
Medium-High & $27(18.4)$ & $71(48.3)$ & $68(46.3)$ & $66(44.9)$ \\
High & $21(14.3)$ & $43(29.3)$ & $49(33.3)$ & $49(33.3)$ \\
Missing $^{\text {a }}$ & $7(4.7)$ & $14(9.5)$ & $14(9.5)$ & $17(11.5)$ \\
\hline
\end{tabular}

a"Missing" refers to those students who did not complete a Free Application for Federal Student Aid (FAFSA) and therefore did not receive a financial need designation 


\section{American Journal of Pharmaceutical Education 2017; 81 (7) Article 5918.}

instrument which suggests these students may have nonfederal student loans. Among the three remaining students from the group $(n=12)$ who stated they had no student loans to pay off in the survey instrument, all had a history of federal student loans: one student had completely paid off their federal loans, while the other two students had unpaid federal student loans remaining per financial aid records.

Figure 1 presents a summary of estimated student loan debt, total federal student loan debt, and pharmacy school student loan debt only for those students who have loans (ie, for those students with loan amounts greater than $\$ 0$ in each category). Figure 2 displays a summary of these same categories for the full sample (in other words, those students who have loans plus those who do not; $n=147$ ). For students with loans prior to pharmacy school, the mean (SD) amount borrowed was \$23,554 $(22,819)$ (ranging from $\$ 700$ to $\$ 131,176$ ). Among students with federal student loans, the mean (SD) amount paid off to date was $\$ 2,970(9,646)$ (ranging from $\$ 0$ to $\$ 71,981$ ).

Table 2 displays the mean scores and standard deviations of the attitudes toward debt sub-scales and
PSS-10 (Perceived Stress Scale). The Cronbach's alpha was .89 for the PSS-10 and .40 for the attitudes toward debt scale (with Cronbach's alpha for the sub-scales of .48 for "contemplation and knowledge about loans,".54 for "fear of debt," and .60 for "tolerant attitudes toward debt"). There were no significant differences between respondents who did and did not have federal student loans on the PSS10 or the attitudes toward debt sub-scales (Table 2). The PSS-10 was significantly correlated to the "fear of debt" sub-scale (Pearson's $r=-.29 ; p<.01$ ), but not the "tolerant attitudes toward debt" sub-scale or the "contemplation and knowledge about loans" sub-scale ( $p>.05$; Table 3 ).

As displayed in Table 3, increased "contemplation and knowledge about loans" was significantly correlated with lower estimated student loan debt $(p<.01)$, total federal student loans borrowed $(p=.01)$, and pharmacy school loan amount $(p<.01)$. Increased "fear of debt" was significantly correlated with higher estimated student loan debt $(p<.01)$, total federal loans borrowed $(p=.03)$, and pharmacy school loan amount $(p=.01)$. No other significant correlations were found between the attitudes toward debt sub-scales and student loan variables (Table 3).

Summary of Mean and Standard Deviation for Estimated Student Loan Debt, Total Federal Student Loan Debt, and Pharmacy School Student Loan Debt of Respondents With Loans

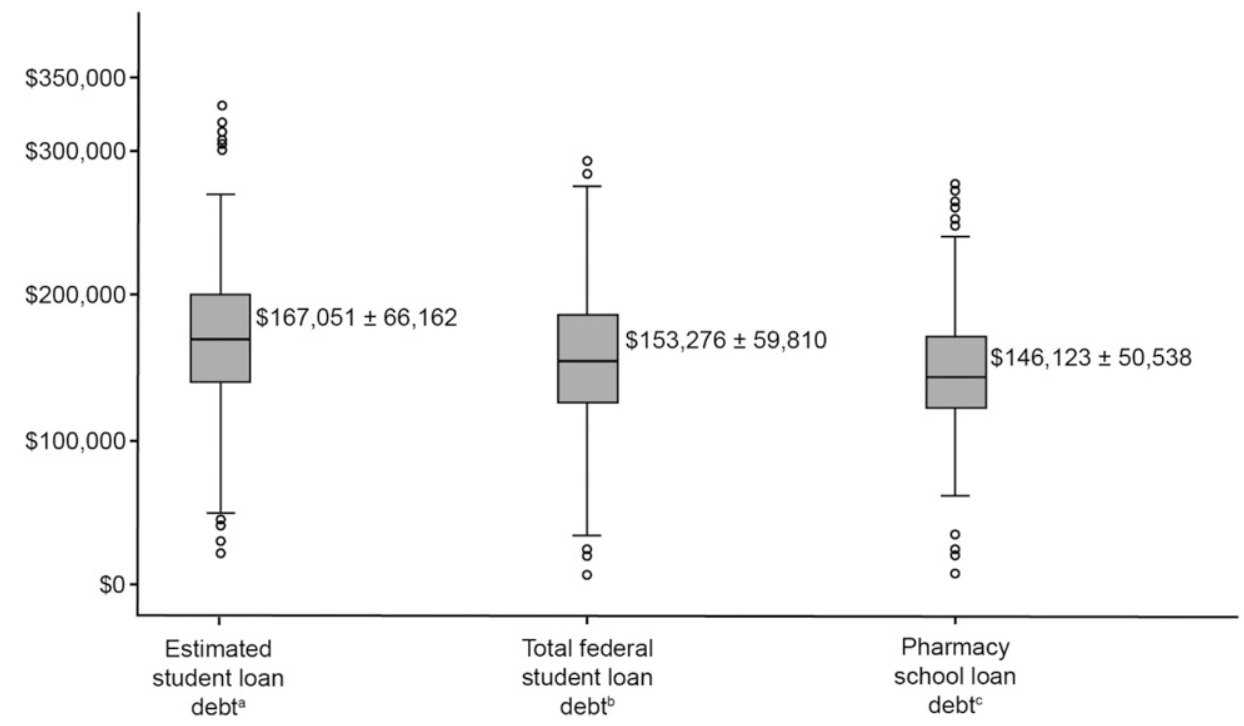

Figure 1 displays the distribution of student loan data only for those students who have greater than $\$ 0$ in each of the three loan categories: estimated student loan debt $(n=131)$; total federal student loan debt $(n=133)$; and pharmacy school loan debt $(n=130)$. The mean and standard deviation of each of the three loan categories are also displayed beside each box plot. The median estimated student loan debt was $\$ 165,000$, median total federal student loan debt was $\$ 152,816$, and median pharmacy school loan debt was $\$ 142,834$ (in the figure, medians were represented by the dark line within each box). The small circles above and below the "whiskers" of the box plot represent data outliers (the whiskers extend to the smallest and largest values within 1.5 box lengths). Refer to the Appendix for presentation of additional distribution data. ${ }^{\text {a }}$ Estimated student loan debt refers to how much students believe they currently owe in student loans accumulated prior to pharmacy school and during pharmacy school. ${ }^{\mathrm{b}}$ Total federal student loan debt refers to a student's accumulated history of federal student loans borrowed prior to pharmacy school and during pharmacy school. ${ }^{\mathrm{c}}$ Pharmacy school student loan debt refers to the amount of federal student loans a student borrowed exclusively during pharmacy school. 


\section{American Journal of Pharmaceutical Education 2017; 81 (7) Article 5918.}

Summary of Mean and Standard Deviation for Estimated Student Loan Debt, Total Federal Student Loan Debt, and Pharmacy School Student Loan Debt of the Full Sample $(n=147)$

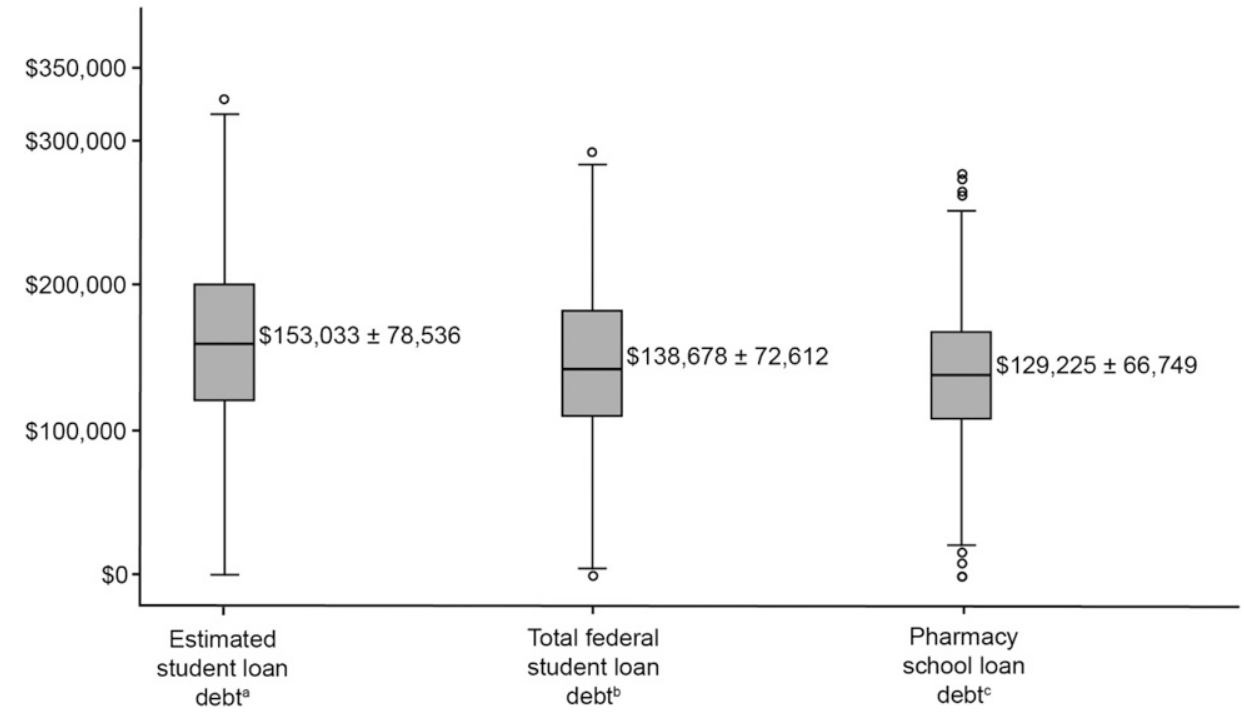

Figure 2 displays the distribution of student loan data for the full sample of 147 students in each of the three loan categories (this includes students who have loans and those who do not have loans). The median estimated student loan debt was $\$ 160,000$, median total federal student loan debt was $\$ 143,962$, and median pharmacy school loan debt was $\$ 138,217$ (in the figure, medians were represented by the dark line within each box). The small circles above and below the "whiskers" of the box plot represent data outliers (the whiskers extend to the smallest and largest values within 1.5 box lengths). Refer to the Appendix for presentation of additional distribution data. ${ }^{a}$ Estimated student loan debt refers to how much students believe they currently owe in student loans accumulated prior to pharmacy school and during pharmacy school. ${ }^{\mathrm{b}}$ Total federal student loan debt refers to a student's accumulated history of federal student loans borrowed prior to pharmacy school and during pharmacy school. ${ }^{\mathrm{c}}$ Pharmacy school student loan debt refers to the amount of federal student loans a student borrowed exclusively during pharmacy school.

No significant differences were found in scores on the three attitudes toward debt sub-scales based on gender, race, current employment, post-graduation plans, or financial need designation. Respondents who expected to repay their student loans in less than 5 years had significantly higher scores on the "contemplation and knowledge about loans" sub-scale than those who expected to repay their loans in greater than 10 years $(<5$ year group mean (SD) 14.9 (2.8) vs. $>10$ year group mean (SD) $12.6(2.5) ; p<.01)$. There were no significant differences based on expected number of years to pay off student loans for the "tolerant attitudes toward debt" sub-scale or the "fear of debt" sub-scale.

\section{DISCUSSION}

Only one previously published study ${ }^{15}$ addressed pharmacy students' attitudes toward debt, and no published studies are available concerning the relationship between said attitudes and stress among pharmacy students. Therefore, the purpose of the current study was to examine the association between pharmacy students' attitudes toward debt and various factors including

Table 2. Comparison of Mean (SD) Scale Scores Between Respondents With and Without Federal Student Loans

\begin{tabular}{lcccc}
\hline Scale & $\begin{array}{c}\text { Total Sample } \\
(\mathbf{n = 1 4 7 )}\end{array}$ & $\begin{array}{c}\text { No Federal } \\
\text { Student Loans Group } \\
(\mathbf{n = 1 4 )}\end{array}$ & $\begin{array}{c}\text { Federal Student } \\
\text { Loans Group } \\
(\mathbf{n = 1 3 3})\end{array}$ & $\boldsymbol{p}$ value \\
\hline "Tolerant attitudes toward debt" sub-scale & $8.83(2.46)$ & $7.79(1.97)$ & $8.94(2.49)$ & .10 \\
"Contemplation and knowledge about loans" sub-scale & $13.88(2.55)$ & $14.36(3.13)$ & $13.83(2.49)$ & .46 \\
"Fear of debt" sub-scale & $7.47(2.37)$ & $7.29(1.20)$ & $7.49(2.46)$ & .60 \\
PSS-10 & $15.87(6.71)$ & $16.93(6.97)$ & $15.76(6.70)$ & .62 \\
\hline
\end{tabular}

PSS, Perceived Stress Scale

Note: "Tolerant attitudes toward debt" sub-scale scores ranged from 4-20, with higher scores indicating more tolerant attitudes toward debt. "Contemplation and knowledge about loans" sub-scale scores ranged from 4-20, with higher scores indicating greater contemplation and knowledge about loans. "Fear of debt" sub-scale scores ranged from 3-15, with higher scores indicating less fear of debt. Scores on the PSS-10 ranged from 0-40, with higher scores indicating greater perceived stress 
American Journal of Pharmaceutical Education 2017; 81 (7) Article 5918.

Table 3. Correlations of Attitudes Toward Debt Sub-scales, the Perceived Stress Scale (PSS-10), Estimated and Actual Student Loan Debt, and Amount Paid Toward Student Loan Debt

\begin{tabular}{|c|c|c|c|c|c|c|c|c|c|}
\hline \multirow{2}{*}{$\begin{array}{l}\text { 1. "Tolerant attitudes } \\
\text { toward debt" sub- } \\
\text { scale }\end{array}$} & 2 & 3 & 4 & 5 & 6 & 7 & 8 & 9 & 10 \\
\hline & & & & & & & & & \\
\hline Pearson $r$ & -.12 & .08 & .12 & .02 & .04 & .08 & -.09 & .10 & -.06 \\
\hline$p$ value & .14 & .36 & .15 & .85 & .63 & .38 & .32 & .28 & .51 \\
\hline $\begin{array}{l}\text { 2. "Contemplation } \\
\text { and knowledge about } \\
\text { loans" sub-scale }\end{array}$ & & & & & & & & & \\
\hline Pearson $r$ & & -.01 & -.12 & -.23 & -.22 & -.24 & -.002 & .02 & -.01 \\
\hline$p$ value & & .92 & .14 & $<.01$ & .01 & $<.01$ & .98 & .86 & .93 \\
\hline $\begin{array}{l}\text { 3. "Fear of debt" sub- } \\
\text { scale }\end{array}$ & & & & & & & & & \\
\hline Pearson $r$ & & & -.29 & -.23 & -.19 & -.21 & .02 & .04 & -.03 \\
\hline$p$ value & & & $<.01$ & $<.01$ & .03 & .01 & .79 & .68 & .69 \\
\hline 4. PSS-10 & & & & & & & & & \\
\hline Pearson $r$ & & & & .05 & .07 & .08 & -.02 & .10 & -.04 \\
\hline$p$ value & & & & .58 & .46 & .38 & .85 & .27 & .60 \\
\hline $\begin{array}{l}\text { 5. Estimated student } \\
\text { loan debt }{ }^{\mathrm{a}}\end{array}$ & & & & & & & & & \\
\hline $\begin{array}{l}\text { Pearson } r \\
p \text { value }\end{array}$ & & & & & $\begin{array}{l}.90 \\
<.01\end{array}$ & $\begin{array}{c}.87 \\
<.01\end{array}$ & $\begin{array}{c}.33 \\
<.01\end{array}$ & $\begin{array}{l}-.36 \\
<.01\end{array}$ & $\begin{array}{l}.25 \\
<.01\end{array}$ \\
\hline $\begin{array}{l}\text { 6. Total federal } \\
\text { student loans } \\
\text { borrowed }\end{array}$ & & & & & & & & & \\
\hline $\begin{array}{l}\text { Pearson } r \\
p \text { value }\end{array}$ & & & & & & $\begin{aligned} & .95 \\
< & .01\end{aligned}$ & $\begin{array}{l}.43 \\
<.01\end{array}$ & $\begin{array}{c}-.11 \\
.19\end{array}$ & $\begin{array}{l}.26 \\
<.01\end{array}$ \\
\hline $\begin{array}{l}\text { 7. Amount of federal } \\
\text { loans taken during } \\
\text { pharmacy school }\end{array}$ & & & & & & & & & \\
\hline $\begin{array}{l}\text { Pearson } r \\
p \text { value }\end{array}$ & & & & & & & $\begin{array}{l}.12 \\
.19\end{array}$ & $\begin{array}{l}-.12 \\
.17\end{array}$ & $\begin{array}{l}.22 \\
.01\end{array}$ \\
\hline $\begin{array}{l}\text { 8. Amount of federal } \\
\text { loans taken prior to } \\
\text { pharmacy school }\end{array}$ & & & & & & & & & \\
\hline $\begin{array}{l}\text { Pearson } r \\
p \text { value }\end{array}$ & & & & & & & & $\begin{array}{l}-.01 \\
.89\end{array}$ & $\begin{array}{l}.18 \\
.04\end{array}$ \\
\hline $\begin{array}{l}\text { 9. Amount of student } \\
\text { loans re-paid to date }\end{array}$ & & & & & & & & & \\
\hline $\begin{array}{l}\text { Pearson } r \\
p \text { value }\end{array}$ & & & & & & & & & $\begin{array}{l}-.05 \\
.60\end{array}$ \\
\hline $\begin{array}{l}\text { 10. Age } \\
\text { Pearson } r \\
p \text { value }\end{array}$ & & & & & & & & & \\
\hline
\end{tabular}

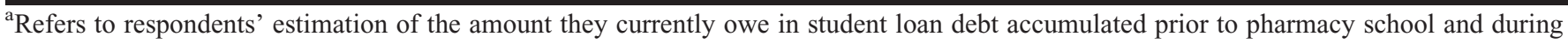
pharmacy school.

perceived stress, estimated student loan debt, actual federal student loan debt, and expected time to repay student loans. Generally, student loans represent the second largest cause of personal debt (following home mortgages) for Americans, and pharmacy students are not excluded from this phenomenon. ${ }^{20}$ Among 133 students with federal loans in this study, $84 \%$ borrowed more than $\$ 100,000$ in student loans, with approximately 20 of these individuals exceeding $\$ 200,000$ in loans. 


\section{American Journal of Pharmaceutical Education 2017; 81 (7) Article 5918.}

In addition to their financial burden, student loans are made an even greater hardship by rigid repayment plans and limited options for loan forgiveness. ${ }^{25}$ As a result, individuals with considerable student loan debt are at increased risk for greater stress and decreased "psychological functioning," as noted by Heckman and colleagues, and Walsemann and colleagues. ${ }^{7,26}$ For example, student loan debt has been linked to stress, burnout, and suicidal thoughts among medical trainees (eg, students and/or residents). ${ }^{14,27-29}$ Cooke and colleagues concluded that undergraduate students with higher debt felt more tense, criticized by others, unhappy, and irritable than students with less or no debt. ${ }^{30}$ Similarly, medical students reported feeling less inclined to social investment, more callous, and more cynical as a result of their debt. ${ }^{14,31}$ Consistent with these studies, the current findings indicated that, on average, graduating pharmacy students have low tolerance and relatively high levels of fear concerning debt. "Fear of debt" was positively correlated with perceived stress among students, indicating that students who were more fearful about debt also experienced greater levels of stress. However, perceived stress was not significantly correlated with estimated or federal student loan amounts. This suggests pharmacy students' fear of debt may play a greater role in triggering stress than the actual amount of debt, which is consistent with Morra and colleagues' report which found that anticipated debt accounted for greater stress among medical students than actual (current) debt. ${ }^{29}$

The study's correlational analysis also indicated that students with greater "fear of debt" had higher estimated student loans, total federal loans, and pharmacy school loans. It is reasonable to assume students with higher debt levels are concerned, anxious, or fearful at the prospect of repaying loans, which likely explains the correlation between the "fear of debt" sub-scale and student loan amounts. The analysis also found that students who had higher scores on the "contemplation and knowledge about loans" sub-scale had lower estimated student loans, total federal loans, and pharmacy school loans. This indicates that students who were more thoughtful and knowledgeable about loans accumulated less student loan debt. Additionally, students with higher "contemplation and knowledge about loans" scores expected to repay their loans within a shorter time frame (less than 5 years) compared to students with lower scores (repayment in greater than 10 years). The findings regarding the "contemplation and knowledge about loans" sub-scale would thus suggest that students who are more thoughtful and knowledgeable regarding loans may take a more measured approach to debt management, understanding that fewer dollars borrowed and quicker repayment results in greater funds saved for personal use. Such a supposition is supported by the findings of Norvilitis and colleagues, who found that increased financial knowledge resulted in less debt among college students. ${ }^{32}$

To further develop understanding of pharmacy students' attitudes and beliefs concerning financial debt and student loans, we compared the mean attitudes toward debt scale item scores of our sample with those of the Park and colleagues' study sample (the only prior published study assessing pharmacy students' attitudes toward financial debt). ${ }^{15}$ The P4 students in the current study had slightly lower scores on the four items in the "tolerant attitudes toward debt" sub-scale than the P2 and P3 students in the Park and colleagues' study. This suggests graduating students, who must soon start paying off student loans, may have somewhat less tolerance for debt than those students who may be relying on said loans to complete their remaining years of pharmacy school. P4 students had higher scores on three of the four "contemplation and knowledge about loans" sub-scale items and all three items of the "fear of debt" sub-scale. This suggests our P4 students had more understanding of loans than the P2 and P3 students in the Park and colleagues' study, which is not surprising given that our students were approaching graduation and had likely begun or completed counseling regarding repayment of student loans. Additionally, the comparison indicates that while our students were relatively fearful of debt, they were slightly less fearful than the students in the Park and colleagues' study. This may be due to graduation-related student loan counseling, as well as having secured employment post-graduation (thus ensuring the means to repay student loans and somewhat lessening fears concerning those loans). In sum, there were small, but noteworthy differences between the two samples on the attitudes toward debt scale that may be attributable to the differing years of pharmacy school represented and/ or education or counseling received.

The cumulative study findings therefore support the need for programming to aid students in better coping with the obligations involved when borrowing and repaying student loans, thus alleviating stress and fear. Similar assertions were made by Rohlfing and colleagues in their study of medical student debt. ${ }^{14}$ Programming that improves knowledge concerning debt and ability to manage debt may include education (both on student loans and general personal finance), financial aid counseling, and professional financial planning. These recommendations are supported by previous studies such as Heckman and colleagues', that noted that college students with greater financial self-efficacy (defined as an individual's perception 


\section{American Journal of Pharmaceutical Education 2017; 81 (7) Article 5918.}

of his or her ability to manage money) experienced less financial stress. ${ }^{26,32}$ In addition to implementing educational, counseling, and planning programs, pharmacy schools may want to consider cost containment as a strategy to reduce students' fear and stress concerning student loans. Pharmacy school tuition has increased dramatically in recent years. Limiting further increases in tuition and fees when possible and providing scholarships to offset costs are mechanisms that may help reduce the need for student loans. Finally, as suggested by Dyrbye and Shanafelt in their study of burnout among medical students and residents, pharmacy schools may consider developing programming focused on student self-care and coping (eg, positive reframing) to help reduce stress associated with student loan debt. $^{27}$

This study has limitations. Although highly significant relationships were found, due to the cross-sectional nature of the study, a causal relationship between variables cannot be established. Although the internal consistency of the PSS-10 was good, the Cronbach's alpha for the attitudes toward debt scale and sub-scales were less than adequate. ${ }^{16,17}$ This may be due to the sample. The psychometrics of the scale were originally established using P2 and P3 students, while our sample included only P4 students who may have had very different reactions to questions concerning debt and student loans given their impending graduation and obligation to begin repayment of student loans. ${ }^{15}$ Future studies using the attitudes toward debt scale should refine and psychometrically reassess the scale for use specifically with P4 students. Additionally, the study was conducted at one college of pharmacy and therefore generalizability may be limited. However, the demographics of the sample were similar to the general pharmacy student population, which supports the greater applicability of study findings. ${ }^{23}$

As higher education costs are likely to increase for the foreseeable future, additional studies are needed on multiple fronts. Financial stress and well-being among pharmacy students and recent graduates should be further explored to determine factors that both predict and mitigate stress and other indicators of psychological and emotional functioning. Educational, counseling, and planning programs should be developed, implemented, and evaluated by pharmacy schools to determine effects on fear of debt, stress, and other financial outcomes such as time to completed student loan repayment. Finally, strategies that directly address the costs of pharmacy school and improve cost-effectiveness for students should be explored.

\section{CONCLUSION}

Our study is the first of its kind to address the knowledge gap concerning the associations between pharmacy students' student loan debt, attitudes toward debt, and stress. The findings indicate that graduating pharmacy students have low tolerance and relatively high levels of fear concerning debt. Additionally, students with higher amounts borrowed were more fearful of debt, and those who were more fearful of debt also experienced greater stress. The prospect and burden of student loan repayment likely plays a role in these findings. Increased contemplation and knowledge about loans was associated with lower amounts borrowed and an expected shorter repayment time frame. Educational programming to increase understanding of loans, debt, and personal financial management may therefore benefit students as they plan on how to finance their pharmacy school expenses.

\section{ACKNOWLEDGMENTS}

The authors would like to thank Samuel Matheny for his assistance in data collection.

\section{REFERENCES}

1. National Center for Education Statistics. Fast facts. http://nces.ed. gov/fastfacts/display.asp?id=98. Accessed February 12, 2016.

2. College Board. Trends in college pricing 2015. http://trends. collegeboard.org/sites/default/files/trends-college-pricing-web-final508-2.pdf. Accessed June 29, 2016.

3. Institute for College Access and Success. Student debt and the class of 2014. October 2015. http://ticas.org/sites/default/files/ pub_files/classof2014.pdf. Accessed June 29, 2016.

4. Kantrowitz M. Why the student loan crisis is even worse than people think. Time. January 11, 2016. http://time.com/money/ 4168510/why-student-loan-crisis-is-worse-than-people-think/. Accessed June 29, 2016.

5. American Association of Colleges of Pharmacy. Graduating student survey information and summary reports. Summary reports for the 2016 graduating student survey. http://www.aacp.org/ resources/research/institutionalresearch/Pages/ GraduatingStudentSurvey.aspx. Accessed September 13, 2016. 6. Nelson MC, Lust K, Story M, Ehlinger E. Credit card debt, stress and key health risk behaviors among college students. Am J Health Promot. 2008;22(6):400-407.

7. Walsemann KM, Gee GC, Gentile D. Sick of our loans: student borrowing and the mental health of young adults in the United States. Soc Sci Med. 2015;124:85-93.

8. Thoits PA. Stress and health: major findings and policy implications. J Health Soc Behav. 2010;51(S):S41-S53.

9. Mott D, Menzel B, Gaither C, Kreling D, Pedersen C, Schommer J. Exploring characteristics of pharmacy student loan debt. $J$ Am Pharm Assoc. 2006; 46(2):266-267.

10. Yusuf AA, Schommer JC, Mott DA, Doucette WR, Gaither CA, Kreling DH. Association between student loan debt on graduation, demographic characteristics and initial choice of practice setting of pharmacists. Innov Pharm. 2011;2(3):Article 51.

11. Andrew M. The changing route to owner occupation: the impact of student debt. Hous Stud. 2010:25(1):39-62.

12. Gicheva D. Does the student-loan burden weigh into the decision to start a family? University of North Carolina-Greensboro 


\section{American Journal of Pharmaceutical Education 2017; 81 (7) Article 5918.}

Department of Economics Working Paper Series. September 2011. http://bae.uncg.edu/assets/research/econwp/2011/11-14.pdf.

Accessed June 29, 2016.

13. Gicheva D. Student loans or marriage? A look at the highly educated. Econ Educ Rev. 2016;53:207-216.

14. Rohlfing J, Navarro R, Maniya OZ, Hughes BD, Rogalsky DK. Medical student debt and major life choices other than specialty. Med Educ Online. 2014;19(1):25603. http://dx.doi.org/10.3402/meo. v19.25603. Accessed September 15, 2016.

15. Park T, Yusuf AA, Hadsall RS. Pharmacy students' attitudes toward debt. Am J Pharm Educ. 2015;79(4):Article 52.

16. DeVellis RF. Scale Development: Theory and Applications. $3^{\text {rd }}$ ed. Thousand Oaks, CA: SAGE Publications; 2012.

17. Vaske JJ. Survey Research and Analysis: Applications in Parks, Recreation and Human Dimensions. State College, PA: Venture Publishing; 2008.

18. Cohen S. Perceived stress scale. 1994. https://www.mindgarden. com/documents/PerceivedStressScale.pdf. Accessed January 15, 2016.

19. Cohen S, Williamson G. Perceived stress in a probability sample of the United States. In Spacapan S, Oskamp S, eds. The Social Psychology of Health: Claremont Symposium on Applied Social Psychology. Newbury Park, CA: Sage; 1988:31-67.

20. Cohen S, Kamarck T, Mermelstein R. A global measure of perceived stress. J Health Soc Behav. 1983;24(4):386-396.

21. Lee E-H. Review of the psychometric evidence of the Perceived Stress Scale. Asian Nurs Res. 2012;6(4):121-127.

22. Roberti JW, Harrington LN, Storch EA. Further psychometric support for the 10-item version of the Perceived Stress Scale. $J$ College Counseling. 2006;9(2):135-147.

23. American Association of Colleges of Pharmacy. Fall 2015 profile of pharmacy students. http://www.aacp.org/resources/research/ institutionalresearch/Pages/StudentApplications,
EnrollmentsandDegreesConferred.aspx. Accessed September 13, 2016.

24. Pipkorn KA, Henk MA. Student loan debt update: a look at a possible future. Milliman. February 17, 2016. http://us.milliman. com/insight/2016/Student-loan-debt-update-A-look-at-a-possiblefuture/?lng= undefined. Accessed June 29, 2016.

25. Walsemann KM, Ailshire JA, Gee GC. Student loans and racial disparities in self-reported sleep duration: evidence from a nationally representative sample of US young adults. J Epidemiol Community Health. 2016 Jan;70(1):42-48.

26. Heckman S, Lim H, Montalto C. Factors related to financial stress among college students. J Financial Therapy. 2014;5(1): Article 3. http://newprairiepress.org/cgi/viewcontent.cgi? article $=1063 \&$ context $=$ jft. Accessed June 29, 2016.

27. Dyrbye L Shanafelt T. A narrative review on burnout experienced by medical students and residents. Med Educ. 2016;50(1):132-149.

28. Dyrbye LN, Harper W, Durning SJ, et al. Patterns of distress in US medical students. Med Teach. 2011;33(10):834-839.

29. Morra DJ, Regehr G, Ginsburg S. Anticipated debt and financial stress in medical students. Med Teach. 2008;30(3):313-315.

30. Cooke R, Barkham M, Audin K, Bradley M, Davy J. Student debt and its relation to student mental health. J Further Higher Educ. 2006:28(1):53-66.

31. Phillips JP, Wilbanks DM, Salinas DF, Doberneck DM. Educational debt in the context of career planning: a qualitative exploration of medical student perceptions. Teach Learn Med. 2016;28:243-251.

32. Norvilitis JM, Merwin MM, Osberg TM, Roehling PV, Young P, Kamas MM. Personality factors, money attitudes, financial knowledge, and credit-card debt in college students. J Appl Soc Psychol. 2006;36(6):1395-1413. 


\section{American Journal of Pharmaceutical Education 2017; 81 (7) Article 5918.}

\section{Appendix}

Histograms a, b, and c display the distribution of each student debt category examined (estimated student loan debt, total federal student lean debt, and pharmacy school student loan debt) only for those students with student loans, ie, those students with loan amounts greater than $\$ 0$ in each category. Also included are means and standard deviations of loan amounts.

a. Estimated Student Loan Debt ${ }^{\mathrm{a}}$ ( $\mathrm{n}=131$ or $89.1 \%$ of the sample), Mean $\$ 167,051(\$ 66,162)$

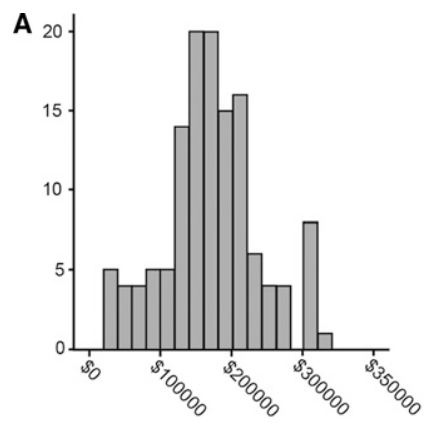

b. Total Federal Student Loan Debt ${ }^{\mathrm{b}}(\mathrm{n}=133$, or $90.5 \%$ of the sample), Mean $\$ 153,276(\$ 59,810)$

B

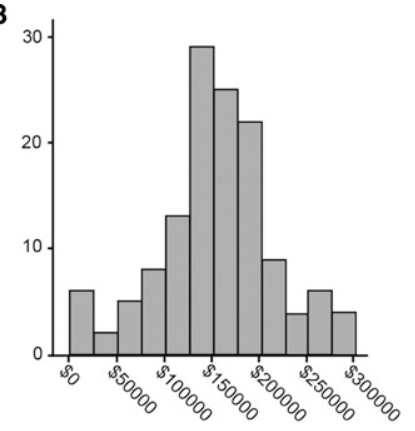

c. Pharmacy School Student Loan Debt ${ }^{\mathrm{c}}(\mathrm{n}=130$, or $88.4 \%$ of the sample), Mean $\$ 146,123(\$ 50,538)$

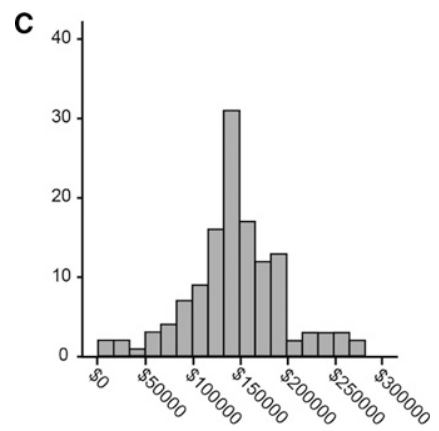




\section{American Journal of Pharmaceutical Education 2017; 81 (7) Article 5918.}

Histograms d, e, and f display the distribution of each student debt category examined (estimated student loan debt, total federal student lean debt, and pharmacy school student loan debt) for all students in the sample $(\mathrm{n}=147)$. Also included are means and standard deviations of loan amounts.

d. Estimated Student Loan Debt ${ }^{\mathrm{a}}$, Mean $\$ 153,033(\$ 78,536)$

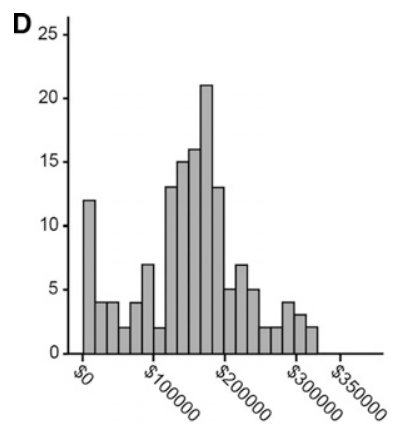

e. Federal Student Loan Debt ${ }^{\mathrm{b}}$, Mean $\$ 138,678(\$ 72,612)$

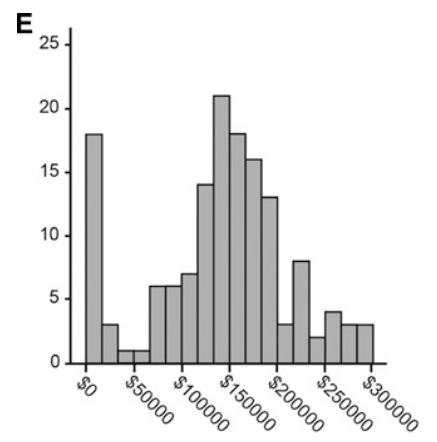

f. Pharmacy School Student Loan Debt ${ }^{\mathrm{c}}$, Mean $\$ 129,225(\$ 66,749)$

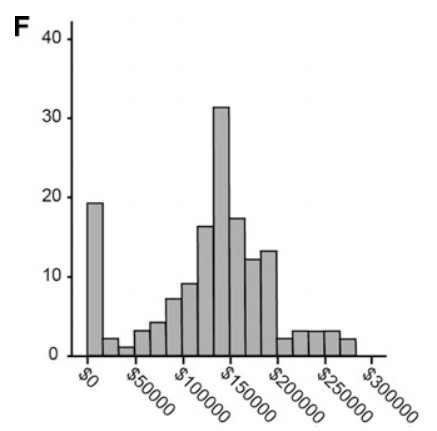

${ }^{a}$ Estimated student loan debt refers to how much students believe they currently owe in student loans accumulated prior to pharmacy school and during pharmacy school. ${ }^{\mathrm{b}}$ Total federal student loan debt refers to a student's accumulated history of federal student loans borrowed prior to pharmacy school and during pharmacy school. ${ }^{\mathrm{c}}$ Pharmacy school student loan debt refers to the amount of federal student loans a student borrowed exclusively during pharmacy school. 